DOI 10.37882/2223-2982.2020.09.31

\title{
ОТЛИЧИЕ ВЛИЯНИЯ ЭТНОКУЛЬТУРНОГО ФАКТОРА РАЗВИТИЯ ИНКЛЮЗИВНОГО ОБРАЗОВАНИЯ В УСЛОВИЯХ РОССИЙСКОЙ И КЫРГЫЗСКОЙ ДЕЙСТВИТЕЛЬНОСТИ (РЕЗУЛЬТАТЫ ИССЛЕДОВАНИЯ)
}

\section{THE INFLUENCE OF THE ETHNO- CULTURAL FACTOR ON THE DEVELOPMENT OF INCLUSIVE EDUCATION IN RUSSIA AND KYRGYZSTAN: THE DIFFERENCES (RESEARCH RESULTS)}

M. Suchkov

Summary: The author carries out a comparative analysis of the influence of ethno-cultural factors on the inclusive education development in Russia and Kyrgyzstan. The peculiarities of ethno-social development and life philosophy of Kyrgyz people which influences the ethnic perception of inclusion are analyzed. The main directions of governmental politics in the equal and accessible education are presented. The author reveals the specifics of inclusive education development in Russia in the context of Russia's integration into global educational space. The experiment described in the article proved the effectiveness of the author's model of inclusive professional education in Russia and Kyrgyzstan which takes into account the ethno-cultural characteristics of the countries.

Keywords: inclusive education, people with disabilities, ethno-cultural factor.

\section{Введение}

И нклюзивное образование, согласно официальным документам ЮНЕСКО, направлено на удовлетворение потребностей всех обучающихся через расширение доступа к образовательным услугам, повышение качества обучения и преодоление отчуждения в социальной среде [1]. Воплощение идеи «образования для всех» подразумевает необходимость значительных изменений в организации процесса обучения, его методики, построении содержательного компонента и в стратегиях управления целой системой образования. Несмотря на общие подходы, цели и задачи инклюзивного образования, существуют значительные различия в специфике и общих тенденциях его развития не только в разных государствах, но и внутри страны в отдельных ее регионах. Эти изменения обусловлены, во-первых, внешними факторами: существующей нормативноправовой базой, особенностями государственного фи-
Сучков Максим Александрович

К.э.н., дочент, Кыргызский филиал ФГБОУ “Казанский национальный исследовательский технологический университет", г. Кант, Кыргызская Республика maksim-suchkov@inbox.ru

Аннотация: В статье автор проводит сравнительную характеристику влияния этнокультурного фактора на специфику развития инклюзивного образования в России и Кыргызстане. Проанализированы особенности этносоциального развития и жизненной философии кыргызского народа, повлиявшие на этническое восприятие идеи инклюзии. Выделены приоритетные направления государственной политики Республики Кыргызстан в сфере равного и доступного образования. Рассмотрены особенности развития инклюзивного образования в России в условиях выхода в глобальное образовательное пространство. На основании проведенного эксперимента доказана эффективность разработанной автором модели развития инклюзивного образования в профессиональных учебных заведениях России и Кыргызстана с учетом этнокультурных особенностей стран.

Ключевые слова: инклюзивное образование, люди с ограниченными возможностями здоровья (ОВЗ), этнокультурный фактор.

нансирования образования, социально-политической обстановкой в стране, уровнем взаимодействия с международными общественными организациями. Во-вторых, существуют внутренние причины, влияющие на особенности развития инклюзивного образования, такие как: общественное мнение, особенности социального восприятия инклюзии в обществе, этнические установки и стереотипы, проявляющие себя в готовности педагогов, родителей, учащихся принимать «всех детей» независимо от их статуса, состояния здоровья, этнической или расовой принадлежности.

\section{Особенности развития инкАюзивного образования в России и Кыргызстане в этнокультурном контексте}

Этнокультурный фактор в развитии инклюзивного образования представляет собой ту движущую силу, которая определяет специфику восприятия, понимания 
идеи равного и доступного образования в стране с точки зрения специфической культуры этноса. Данный фактор складывается из многих составляющих, а именно: особенностей этнического характера, общественного быта, материальной и нематериальной культуры этноса, этнических стереотипов, менталитета и других этнокультурных особенностей [2].

Для изучения специфики этносоциального развития кыргызского народа, отразившейся на особенностях внедрения инклюзивного образования в Кыргызстане, мы обратились к исследованиям А.А. Асанканова, О.И. Брусиной и А.3. Жапарова [3]. По мнению авторов, Республике характерны такие сложные социальные проблемы, как: экономический спад, повлекший за собой снижение уровня образования, массовая трудовая миграция коренных жителей за пределы страны, внутренняя сельско-городская миграция. Высокий уровень безработицы и коррупции, социальная напряженность повлияли на необходимость массового обращения людей к религии в поиске справедливости, что в последующем отразилось на радикализации ислама. Н.С. Мырзабаева [4] также отмечает в Республике рост экстремистских религиозных течений и серьезную этноконфессиональную напряженность на юге страны. Эти особенности повлияли на развитие знаний и ценностей в сфере религии среди детей и подростков, на уровень их безопасности. Другой этнорелигиозной особенностью является то, что кыргызы по сей день воспринимают многие социальные явления не только с позиции ислама, но и других форм религиозного сознания, таких как: тенгрианство, культ предков, суеверия, архаичные синдромы, магия, шаманизм, археотипы и др.

Обращаясь к культуре и самобытности Кыргызстана, мы выделяем те характерные особенности, которые, с одной стороны, создают благоприятную почву для развития инклюзии, сплоченности и толерантности, но также являются серьезной преградой для внедрения идей инклюзии. К примеру, кочевнический дух кыргызского народа сформировал чувство коллективизма и открытость к диалогу. Кочевая община, как главный традиционный институт кыргызского общества, имел важнейшую функцию поддержания прочных социальных, производственных и бытовых связей. Многие решения принимались в общине с опорой на коллективные эмпирические знания. Кыргызы вместе разделяли радость и горечь кого-либо из членов такой общины. В советское время также сохранялись общинные традиции, поддерживались прочные духовные и хозяйственные связи путем интеграции семей в соседско-территориальную общину [3].

3.К. Дербишева [5] в исследовании жизненной философии кыргызов подчеркивает, что важнейшими ценностями народа являются его сплоченность и единство, нравственная щедрость, надежда на лучшее будущее, справедливость, значимость умственного и физического труда. В инклюзивной образовательной среде такие жизненные приоритеты, безусловно, способствуют формированию толерантности, взаимоуважения и взаимоподдержки среди педагогов и обучающихся.

С другой стороны, в исследованиях А.А. Асанканова [3] о социальной иерархии кыргызов отмечено, что в обществе существовала строгая стратификация по социально-профессиональным, имущественным, половозрастным признакам. Известная кыргызская поговорка «Баатыр алтоо, бай төртөө, кедей сигиз, бий жалгыз, кул тогуз» (шесть богатырей, четыре бая, восемь бедняков, единственный бий, девять рабов) говорила о серьезном расслоении в кыргызском обществе, несмотря на то, что допускалось свободное перемещение в другую социальную страту.

Особое положение женщины в Кыргызстане в традиционном понимании отразилось на такой серьезной проблеме, как раннее выбывание из системы образования в связи с вступлением в брачные отношения [6]. Данное социальное явление имеет свои исторические корни. Например, мир женщины раньше ограничивался собственной юртой, айылой (селением кочевого и полукочевого типа). Ее основная функция заключалась в ведении домашнего хозяйства, воспитании детей, в участии в трудовой деятельности в рамках семейно-родственной группы [3] Однако жизнь ее не была затворнической, она также имела большой авторитет, с ее мнением считались и другие члены семьи.

Вышеперечисленные этнокультурные особенности страны, а также внешние факторы, повлияли на следующие специфические черты развития инклюзивного образования в Республике Кыргызстан:

1. низкий уровень грамотности населения приводит к недостаточной осведомленности родителей о правах своих детей;

2. недостаточная проработка в Республике стандартов, регулирующих предоставление качественного образования для детей с ограниченными возможностями здоровья (ОВ3) повлекла за собой отсутствие доступа всех детей к образовательным услугам;

3. высокий уровень трудовой миграции способствовал низкому уровню грамотности населения, а далее - к безработице, уязвимости населения, склонности к криминальному поведению.

Несмотря на определенные пробелы в области инклюзивного образования, Правительство Республики начало осуществлять серьезные меры по модернизации данной сферы. Правительством разработана Концепция по внедрению инклюзивного образования на 2019-2023 
годы [7] и Национальная стратегия развития Кыргызской Республики на 2018-2040 годы [8] , направленные на внедрение дополнительных механизмов и ресурсов для сферы инклюзивного образования, осуществление подготовки и повышение квалификации педагогов, преодоление дискриминационных установок в обществе по религиозным, этническим и родоплеменным признакам.

Особенностью социального развития, повлиявшей на инклюзивное образование в Республике, является также привнесение элементов гражданского общества и социальных преобразований со стороны международных неправительственных организаций из США, Германии, правозащитных организаций ООН. Например, в рамках сотрудничества Правительства Республики с Агентством США по международному развитию осуществляются проекты по повышению грамотности среди населения («Читаем вместе», «Время для чтения» и другие). Совместно с ЮНИСЕФ Правительством Республики апробированы различные механизмы инклюзивного обучения в дошкольных и общеобразовательных учреждениях. В Республике реализованы проекты, направленные на поддержание многоязычия и создание среды, способствующей широкой интеграции этнических меньшинств. Итак, Правительство совершает ряд важных шагов на пути внедрения инклюзивного образования, активно взаимодействуя с различными международными организациями и реализуя значимые социальные проекты в данной сфере.

Таким образом, вектор развития инклюзивного образования в Республике происходит на пересечении ярковыраженной этнокультурной линии, с одной стороны, и развивающихся демократических процессов в современном Кыргызстане, с другой стороны.

Развитие инклюзивного образования в России также имеет свои специфические особенности, сформированные под влиянием социального уклада и духовного облика народов России, а также с учетом выхода страны в международное образовательное пространство. В Законе «Об образовании в Российской Федерации» № 273-Ф3 [9] закреплена возможность организации образовательного процесса для обучающихся с ОВ3 как совместно с другими учащимися, так и в отдельных группах или организациях, осуществляющих образовательную деятельность. Кроме того пп.1. п.5. ст.5 закрепляет создание органами власти необходимых условий для получения качественного образования без дискриминации лицами с ОВ3 посредством организации инклюзивного образования. Существуют и другие нормативно-правовые акты и государственные национальные программы, регулирующие данную сферу, например: «Федеральный Закон о социальной защите инвалидов в РФ», «Государственная программа развития образования на 2018-2025 годы» и др.
Однако инклюзивное образование подразумевает не только организацию обучения лиц с умственными или физическими отклонениями. С учетом многонациональности российского общества, инклюзивное образование - это также организация доступного и качественного обучения для студентов-иностранцев, этнических меньшинств, людей другой расовой принадлежности. [10].

В исследованиях Н.А. Симбирцевой и Н.С. Шульги [11] об особенностях поликультурного образования в России отмечено, что современная культурно-образовательная политика страны нацелена на поддержание культурного многообразия, формирование поликультурного мировоззрения обучающихся. Кроме того, многие государственные программы страны направлены на развитие патриотических чувств и уважения к культуре и традициям этносов России, толерантности к окружающим вне зависимости от их этнической принадлежности.

Формированию культурно разнообразной образовательной среды в российских учебных заведениях также способствует высокий уровень внутренней миграции вследствие существенной дифференциации в уровне жизни населения в разных регионах России. Центральный, Северо-Западный и Южный федеральные округа нашей страны являются наиболее заселенными. Следовательно, среда в образовательных учреждениях этих округов является этнически разнообразной.

Не только внутренняя, но и внешняя миграция способствует усилению полиэтничности российского образования. За период 2007-2017 годы наблюдался рост численности мигрирующих в Россию из стран Ближнего Зарубежья, преимущественно из СНГ, при этом большая часть из Армении, Молдавии, Таджикистана, а также из других государств (Грузии, Эстонии, Латвии, КНДР). Согласно статистике Министерства образования и науки возросла численность студентов, обучающихся в российских вузах, по сравнению с 2010 годом на 244,9 тыс. человек. Большая их часть обучается в учебных заведениях Центрального, Приволжского и Сибирского федеральных округов [12].

Другой характерной чертой развития инклюзивного образования в России является особое, порой противоречивое, восприятие инклюзии в призме «российской ментальности». С одной стороны, под влиянием господствующей православной религии в народном менталитете сформированы такие ценности, как: уважительное и доброжелательное отношение к людям, готовность прийти на помощь нуждающимся, проявление милосердия и терпения по отношению к ближнему, преобладание духовных ценностей над материальными. Общинная организация жизни русского этноса сформировала чувство коллективизма, желание помогать ближнему («Один в 
поле не воин»). С другой стороны, в стране продолжает существовать серьезное социальное неравенство, особенно, ввиду разного уровня доходов населения. Эта проблема является следствием неразвитости гражданского общества, чрезмерной бюрократизации власти и других социально-политических проблем. Н.Г. Скворцов [13] подчеркивает такую особенность, как этническое неравенство, подразумевающее наличие разных ресурсных возможностей у различных этнических групп (экономических, политических и др.). В России социальное неравенство закрепляется в этническом и массовом сознании, усиливает стратификацию общества, что в дальнейшем приводит к социальной несправедливости.

Важно также подчеркнуть, что разные этносы России (горские народы Кавказа, народы Западной и Восточной Сибири, Дальнего Востока, Севера, Поволжья) имеют свойственный им менталитет, жизненные ценности и, следовательно, воспринимают идеи инклюзивного образования в собственной этноментальной призме.

\section{Ход и результаты эксперимента}

В рамках исследования мы разработали инновационную модель развития инклюзивного образования в профессиональных учебных заведениях России и Кыргызстана, включающую в себя ряд технологий и методов инклюзивного обучения, стратегию повышения психолого-педагогической и межкультурной компетенций студентов и преподавателей с учетом этнокультурной специфики стран. Нами создан и внедрен элективный курс для студентов «Этнокультурные аспекты внедрения идей инклюзивного образования» (36 часов). С целью повышения готовности преподавателей к организации инклюзивного образовательного процесса мы разработали ряд методологических семинаров и тренингов, направленных на формирование общекультурной профессиональной компетенции педагогов, знаний методики и технологий инклюзивного обучения.

В эксперименте по апробации данной модели приняли участие 250 студентов и 90 преподавателей Кыргызского филиала ФГБОУ «Казанский национальный исследовательский технологический университет» (Кыргызский филиал КНИТУ, г. Кант, Кыргызстан), а также 250 студентов и 90 преподавателей Казанского инновационного университета им. В.Г. Тимирясова (КИУ им. В.Г. Тимирясова, Казань, Россия).

Эффективность разработанной модели оценивалась на основании нескольких показателей. Ниже представлены некоторые из них:

1. степень психолого-педагогической готовности преподавателей к работе в инклюзивной образовательной среде, а также готовности студентов к совместному обучению со сверстниками, имею- щими ОВ3, другую этническую принадлежность;

2. уровень этнокультурной компетентности преподавателей и студентов, выражающейся в совокупности представлений и знаний о собственной этнической культуре и других культурах, осознании ценностей других культур и способности к взаимопониманию.

Для выявления данных показателей было проведено анкетирование среди студентов и преподавателей, отдельно осуществлялось наблюдение за ходом образовательного процесса, использовались методы педагогической рефлексии. Ниже представлены результаты проведенного исследования до и после эксперимента (рис.1 и рис.2)

На диаграммах мы видим, что студенты КИУ им. В.Г. Тимирясова до проведения эксперимента показали более высокую степень готовность к совместному обучению, чем студенты Кыргызского филиала (на $12 \%$ ). Российские преподаватели также имели более высокую степень психолого-педагогической готовности к преподаванию в инклюзивной среде по сравнению с преподавателями из Кыргызстана.

Далее мы провели ряд методологических семинаров для педагогов российского и кыргызского вузов, описанных ранее. Студенты прошли обучение по элективному курсу «Этнокультурные аспекты внедрения идей инклюзивного образования». Педагоги и студенты также приняли участие в тренингах по межкультурной коммуникации и сензитивности. В образовательный и воспитательный процесс были внедрены разработанные нами технологии и методы инклюзивного обучения с учетом этнокультурных особенностей стран. После проведения данных мероприятий отметилась положительная динамика в степени готовности педагогов к работе в инклюзивной среде и студентов - к совместному обучению, как в Республике Кыргызстан, так и в России. Уровень межкультурной компетенции педагогов и студентов в российском вузе был выше, чем в Кыргызстане. В результате анкетирования было выявлено, что преподаватели из Республики Кыргызстан (на 12 \% больше по сравнению с преподавателями из России) большое значение придают этнокультурным аспектам в образовательном процессе, считают необходимым приобщать обучающихся к национальным обычаям, ценностям, развивать нравственно-духовные качества через интерес к истории и народному творчеству кыргызского этноса.

Итак, проведенный эксперимент доказал эффективность предложенной нами модели развития инклюзивного образования в профессиональных учебных заведениях России и Кыргызстана в этнокультурной призме, а именно:

- повысилась эффективность инклюзивного обра- 
Преподаватели из России Преподаватели из Кыргызстана

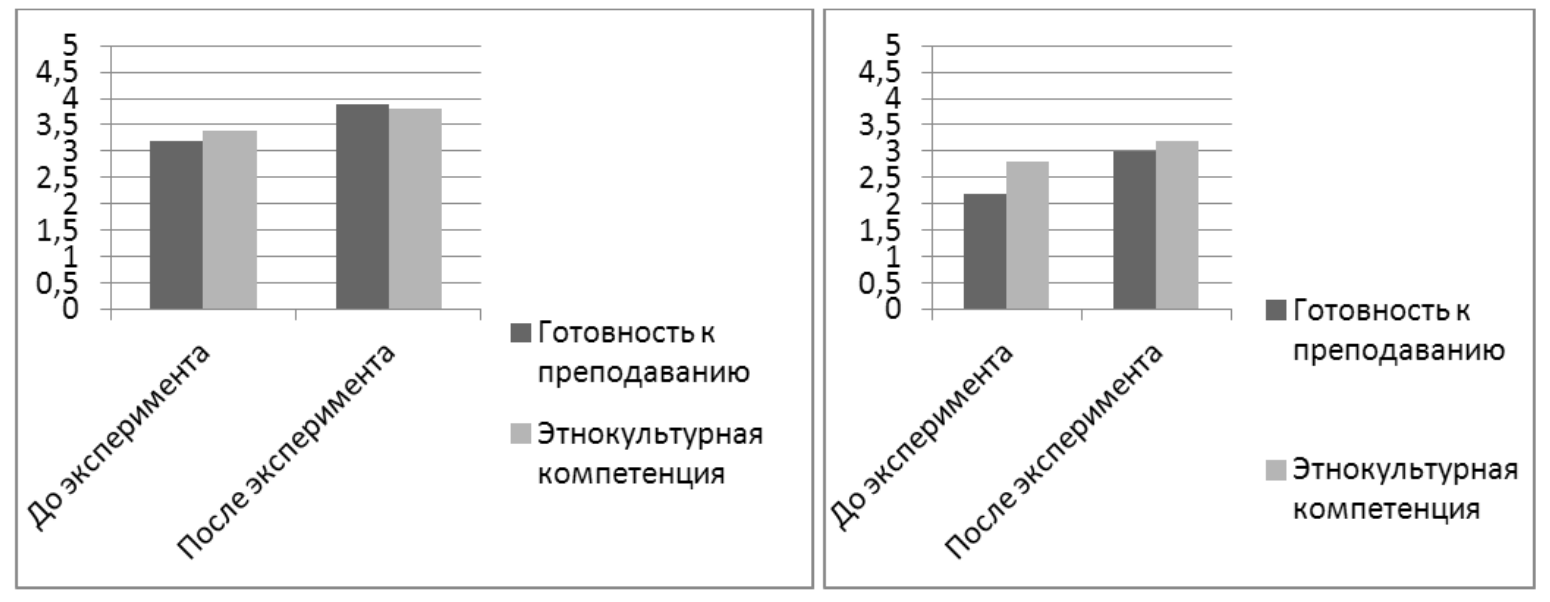

Рис. 1. Динамика диагностируемых показателей в группах преподавателей из России и Республики Кыргызстан до и после эксперимента

Студенты из России Студенты из Кыргызстана

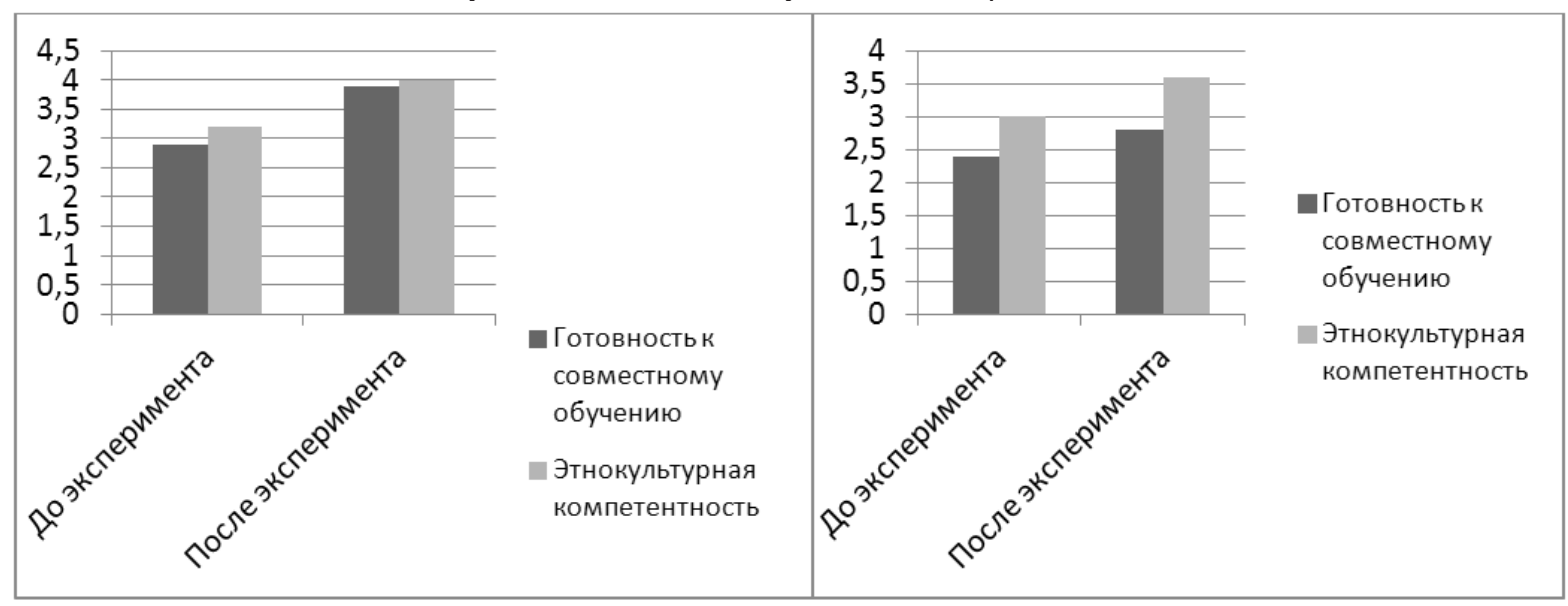

Рис. 2. Динамика диагностируемых показателей в группах студентов из России и Республики Кыргызстан до и после эксперимента

зовательного процесса;

- была преодолена негативная социальная перцепция в отношении студентов с ОВ3 и других этнических принадлежностей, были снижены этноцентристские установки;

- возрос уровень владения технологиями инклюзивного образования среди педагогов и общий уровень осведомленности о психолого-педагогических аспектах инклюзивного образования.

\section{Зак^ючение}

Инклюзивное образование в Республике Кыргызстан имеет свой «самобытный» характер ввиду менталитета, сильной приверженности культурным традициям, народным ценностям. Тем не менее, модернизация разных сфер общественной жизни в Республике ставит задачи адаптации существующей образовательной системы к новым реалиям и условиям. Кроме того, инклюзивное образование развивается с участием организаций «извне», которые в своей деятельности нацелены на решение вопросов этнической гармонии, гендерного равенства, помощи людям с ОВ3, предотвращение конфликтов на этнорелигиозной основе.

На основании проведенного эксперимента было выявлено, что уровень развития инклюзивного образования в России выше по сравнению с Республикой Кыргызстан по ряду показателей. Тем не менее, российское образование, особенно с учетом его возрастающей полиэтничности, также нуждается в более проработанных механизмах создания доступной образовательной среды, обучающих программ, в грамотном учете международного опыта, а главное, в трансформации общественного сознания с целью формирования положительного восприятия идеи «образования для всех». 


\section{ЛИТЕРАТУРА}

1. Promoting Inclusive Teacher Education. URL: https://en.unesco.org/inclusivepolicylab/sites/default/files/learning/document/2017/1/221033e.pdf

2. Сучков М.А. Этнокультурный фактор развития инклюзивного образования (на примере Российской Федерации и Республики Кыргызстан) // Высшее образование в России. -2020. - Т. 29. №5. - С.127-135. URL: https://doi.org/10.31992/0869-3617-2020-29-5-127-135

3. Асанканов А.А., Брусина 0.И., Жапаров А.3. Кыргызы; Ин-т истории и культурного наследия НАН КР. - М.: Наука, 2016.- 623 с.

4. Мырзабаева Н.С. Религиозная ситуация в современном Кыргызстане // Наука, техника и образование. - 2017. - Том 1. № 5 (35). - С.88-93.

5. Дербишева 3.К. Кыргызский этнос в зеркале языка: монография. - 2-е изд. - М.:ФЛИНТА, 2015. - 211 с.

6. Кочорбаева 3.И., Пригода Н.П., Орестис С. Гендерное и инклюзивное измерение образования в Кыргызской Республике. Аналитический обзор. - Бишкек. $-2016 .-56 c$.

7. Концепция развития инклюзивного образования в Кыргызской Республике на 2019-2023 годы. URL: http://cbd.minjust.gov.kg/act/view/ru-ru/14591

8. Национальная стратегия развития Кыргызской Республики на 2018-2040 годы. URL: http://www.stat.kg/ru/nsur/

9. Федеральный Закон от 29.12.2012 г. № 273 Ф3 «06 образовании в Российской Федерации». URL: http://www.consultant.ru/document/cons_doc_ LAW_140174/

10. Ахметова Д.З., Нигматов 3.Г., Челнокова Т.А., Юсупова Г.В. Педагогика и психология инклюзивного образования: учебное пособие. - Казань: Познание, 2019. $-174 \mathrm{C}$.

11. Симбирцева Н.А., Шульга Н.С. Поликультурное образование как направление деятельности открытого университета // Педагогическое образование в России. - 2017. - № 8.- - .6-12.

12. Наука TACC. URL: https://nauka.tass.ru/nauka/7562175

13. Скворцов Н.Г., Верещагина А.В., Самыгин С.И. Социальное неравенство в России: вызовы национальной идентичности // Гуманитарные, социально-экономические и общественные науки. - 2016. - № 10. - С. 95-102.

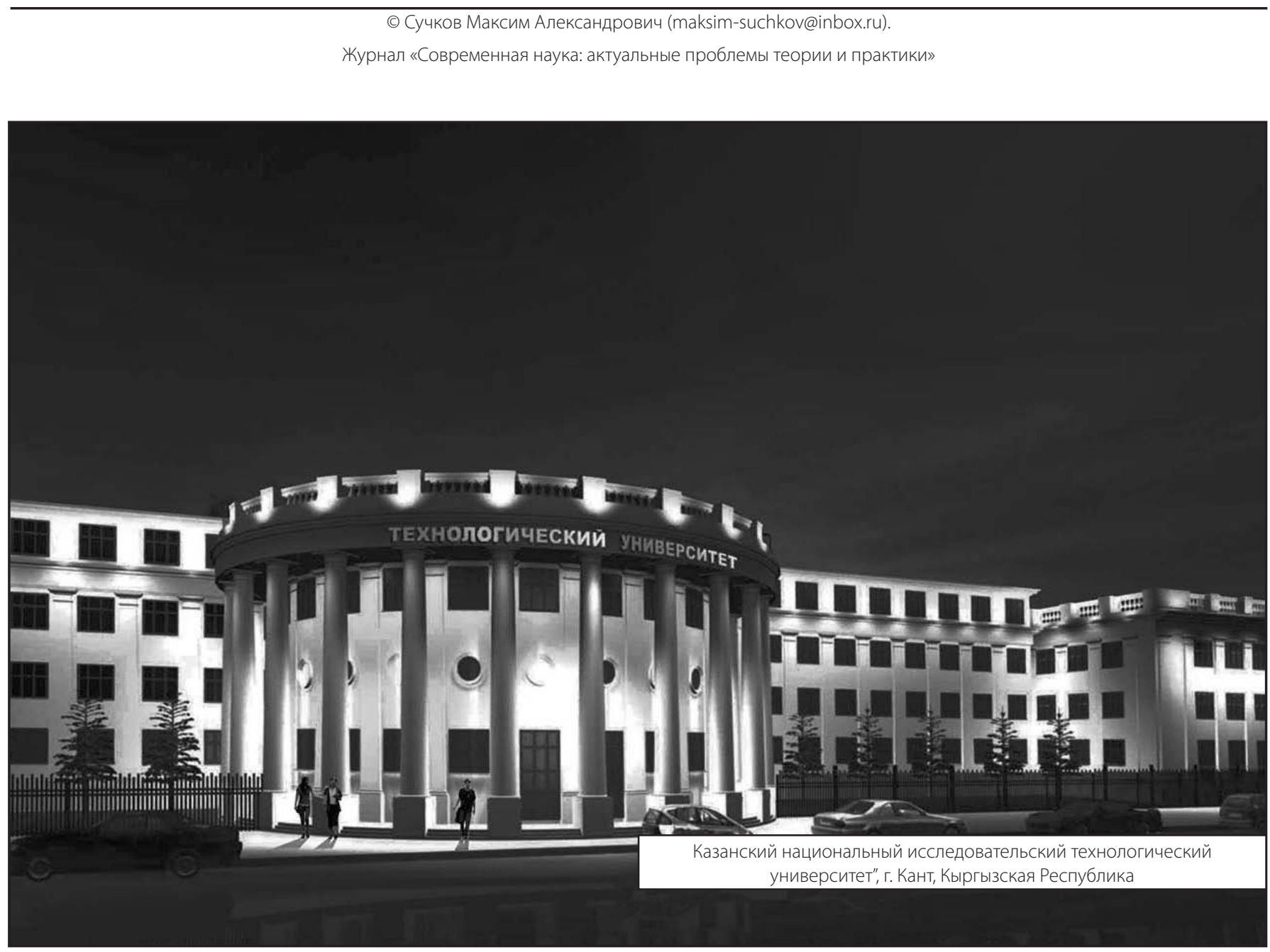

